\title{
Revisão/ Review
}

\section{Anemia de D oença C rônica}

Rodolfo D. Cançado ${ }^{1}$
Carlos S. Chiattone
Anemia de Doen ça Crônica (ADC) éusualmente definida como a anemia que ocorre em distúrbios infecciosos crônicos, inflamatórios ou doenças neoplásicas, e é uma das síndromes clínicas mais comuns na prática clínica. Caracteristicamente, ADC correspon deà an emia normocrômica/ normocítica, leve a moderada, e caracteriza-se por hipoferremia na presença de estoques adequados de ferro.

Os três principais mecanismos patológicos envolvidos na ADC são: diminuição da sobrevida da hemácia, falha da medula óssea em aumentar a produção de glóbulos vermelhos para compensar o aumen to da sua demanda, e distúrbio da mobilização do ferro de depósito do sistema mononuclear fagocitário. 0 papel central dos monócitos e dos macrófagos e o aumento da produção de citocinas mediadoras da resposta imune ou inflamatória, tais como: TNF $\alpha$, INF $\gamma$ e IL-1 estão implicados nos três processos envolvidos no desenvolvimento da ADC. 0 propósito desse artigo é revisar os recentes avan ços no enten dimento dos aspectos patofisiológico, diagnóstico e terapêutico desta síndrome. Rev.bras. hematol.hemoter.,2002,24(2):127-136

Palavras-chave: Anemia de doença crônica, citocinas, fator de necrose tumoral, inteleucina, interferon

\section{D efinição e T erminologia}

Anemia de Doença Crônica é uma síndrome clínica que se caracteriza pelo desenvolvimento de anemia em pacientes que apresentam doenças infecciosas crônicas, inflamatórias ou neoplásicas $(1,2,3)$. Essa síndrome tem como aspecto peculiar a presença de anemia associada à diminuição da concentração do ferro sérico e da capacidade total de ligação do ferro, embora a quantidade do ferro medular seja normal ou aumentada $(2,4)$.

Por definição, não fazem parte dessa síndrome outras causas de anemia como: perda sangüínea, deficiência de ferro, deficiência de folato e/ou vitamina B12, hemólise, mielofitise, doença renal, doença endócrina e doença hepática, exposição a drogas e/ou toxinas, embora essas causas possam coexistir no mesmo paciente (5).

0 termo Anemia de Doença Crônica (ADC) foi proposto pela primeira vez por Cartwrigt, em 1966, após vários anos estudando o binômio infecção e anemia (6).

0 termo ADC é inapropriado, visto que nem toda doença crônica cursa com anemia e nem toda anemia presente no paciente com doença crônica é devido à ADC (7). Desde a década de 70, várias denominações foram propostas como: anemia ferropênica com siderose reticuloendotelial (6), anemia por defeito de reutilização do ferro (7), anemia hipoferrêmica valiosa e

1 - Professor assistente da Disciplina de Hematologia e Oncologia da Faculdade de Ciências Médicas da Santa Casa de São Paulo e do Hemocentro da Santa Casa de São Paulo

2 - Chefe da Disciplina de Hematologia e Oncologia da Faculdade de Ciências Médicas da Santa Casa de São Paulo e do Hemocentro da Santa Casa de São Paulo

Correspondência para: Rodolfo Delfini Cançado

Hemocentro da Santa Casa de São Paulo

Rua Marquês de Itú, 579 - 2o andar. CEP: 01223-001. São Paulo. SP

E-mail: rdcan@uol.com.br 
anemia da inflamação (8). Entretanto, até 0 momento, o termo ADC tem sido utilizado pela maioria dos autores e periódicos nacionais e internacionais.

\section{Freqüência}

ADC é a causa mais freqüente de anemia em pacientes hospitalizados (9), particularmente quando se analisa pacientes com idade superior a 65 anos, e a segunda causa mais freqüente de anemia, após a anemia por deficiência de ferro. Cash \& Sears, analisando pacientes anêmicos sem história de perda sangüínea, observaram que 52\% dos pacientes estudados preenchiam critérios laboratoriais para o diagnóstico de ADC (ferro sérico diminuído e aumento da ferritina sérica) (10). Em pacientes com artrite reumatóide, a freqüência de ADC varia entre $27 \%$ e $58 \%$ (11), sendo essa freqüência maior nos casos em que a doença de base encontra-se em atividade clínica.

Portanto, ADC é uma das síndromes clínicas mais comuns na prática médica impondo, desta forma, ao clínico geral e ao hematologista a necessidade de se familiarizar com essa entidade (5).

\section{Condições Associadas}

ADC está comumente associada às doenças inflamatórias crônicas como artrite reumatóide, às infecções crônicas como tuberculose ou infecções fúngicas sistêmicas, e à neoplasia $(12,13)$. $\mathrm{Na}$ tabela 1 relacionamos as condições patológicas mais freqüentemente associadas à $A D C$.

A artrite reumatóide é uma doença crônica, de caráter inflamatório, classificada como uma das doenças difusas do tecido conjuntivo, de evolução geralmente progressiva e que se caracteriza, fundamentalmente, pelo acometimento do sistema ósteo-articular. No entanto, muitas vezes, esta assume aspecto disseminado, comprometendo diferentes estruturas e sistemas extra-articulares (pulmões, coração, olhos, sangue, etc.). Das alterações sangüíneas, a ADC constitui-se num achado freqüente e é uma das manifestações extraarticulares mais comuns. Isto justifica o fato da maioria dos estudos sobre ADC envolverem pacientes com artrite reumatóide (14).
Tabela 1. Condições patológicas associadas à Anemia de Doença Crônica

\section{Infecções Crônicas (fúngicas, bacterianas, virais)}

Tuberculose, bronquiectasia, abcesso

pulmonar, pneumonia

Endocardite, miocardite, osteomielite, meningite

Doença inflamatória pélvica

Infecção pelo HIV, parvovírus B19

Doenças Inflamatórias Crônicas

Artrite reumatóide, febre reumática, lupus eritematoso sistêmico

Doença de Crohn, sarcoidose

\section{Doenças Neoplásicas}

Linfoma, Mieloma Múltiplo, Carcinoma

\section{Patogênese}

Dos vários mecanismos envolvidos na etiopatogenia da $A D C$, os três principais são: diminuição da sobrevida das hemácias, resposta medular inadequada frente à anemia e distúrbio do metabolismo do ferro $(13,14)$.

A ADC compreende uma das alterações de um complexo de respostas metabólicas frente à estimulação do sistema imunológico celular. Esta resposta inicia-se com a ativação dos macrófagos e a elaboração e secreção de citocinas. Tem sido cada vez mais evidente a participação central dos monócitos e macrófagos na patogênese da ADC (15).

\section{Diminuição da sobrevida das hemácias}

A constatação de que hemácias de indivíduo normal administradas à paciente com artrite reumatóide apresenta sobrevida menor, enquanto que hemácias de indivíduo com artrite reumatóide administradas à indivíduo normal, passam a apresentar sobrevida normal demonstra presença de mecanismo hemolítico extra-globular. Esse 
achado tem sido atribuído ao estado de hiperatividade do sistema mononuclear fagocitário desencadeado por processo infeccioso, inflamatório ou neoplásico. Tal estado hiperreativo leva à remoção precoce dos eritrócitos circulantes e, portanto, à diminuição da sobrevida das hemácias, que varia de 80 a 90 dias, considerando o normal de 110 a 120 dias $(16,17)$.

$O$ utros fatores como: febre (que pode causar dano à membrana eritrocitária), liberação de hemolisinas (em algumas neoplasias) e liberação de toxinas bacterianas podem levar à condição de hiper-hemólise.

\section{Resposta medular inadequada}

No paciente com ADC, a eritropoese encontra-se normal ou discretamente aumentada e a contagem de reticulócitos normal ou inadequadamente aumentada frente ao grau de anemia do paciente.

A resposta medular inadequada observada deve-se, basicamente à secreção inapropriadamente baixa de eritropoetina (EPO), à diminuição da resposta da medula óssea à EPO e à diminuição da eritropoese conseqüente à menor oferta de ferro à medula óssea (13).

A medula óssea normal é capaz de aumentar 6 a 8 vezes sua capacidade eritropoética e, portanto, facilmente compensaria a diminuição modesta da sobrevida das hemácias. No entanto, não é isto que se observa nos pacientes com ADC. Tal falha do aumento da eritropoese deve-se, particularmente, à secreção inapropriadamente baixa de EPO. Normalmente, existe correlação positiva entre síntese de eritropoetina e intensidade da anemia, ou seja, a diminuição da hemoglobina promove aumento da secreção da eritropoetina em indivíduos com função renal normal. Entretanto, vários trabalhos têm mostrado que nos pacientes com artrite reumatóide e ADC tal aumento ocorre, porém é muito pequeno quando comparado ao aumento observado nos indivíduos com artrite reumatóide sem ADC, o qual é capaz de corrigir a anemia $(5,14)$.

Uma das explicações para essa resposta medular inadequada está diretamente relacionada à ativação dos macrófagos e à liberação de citocinas

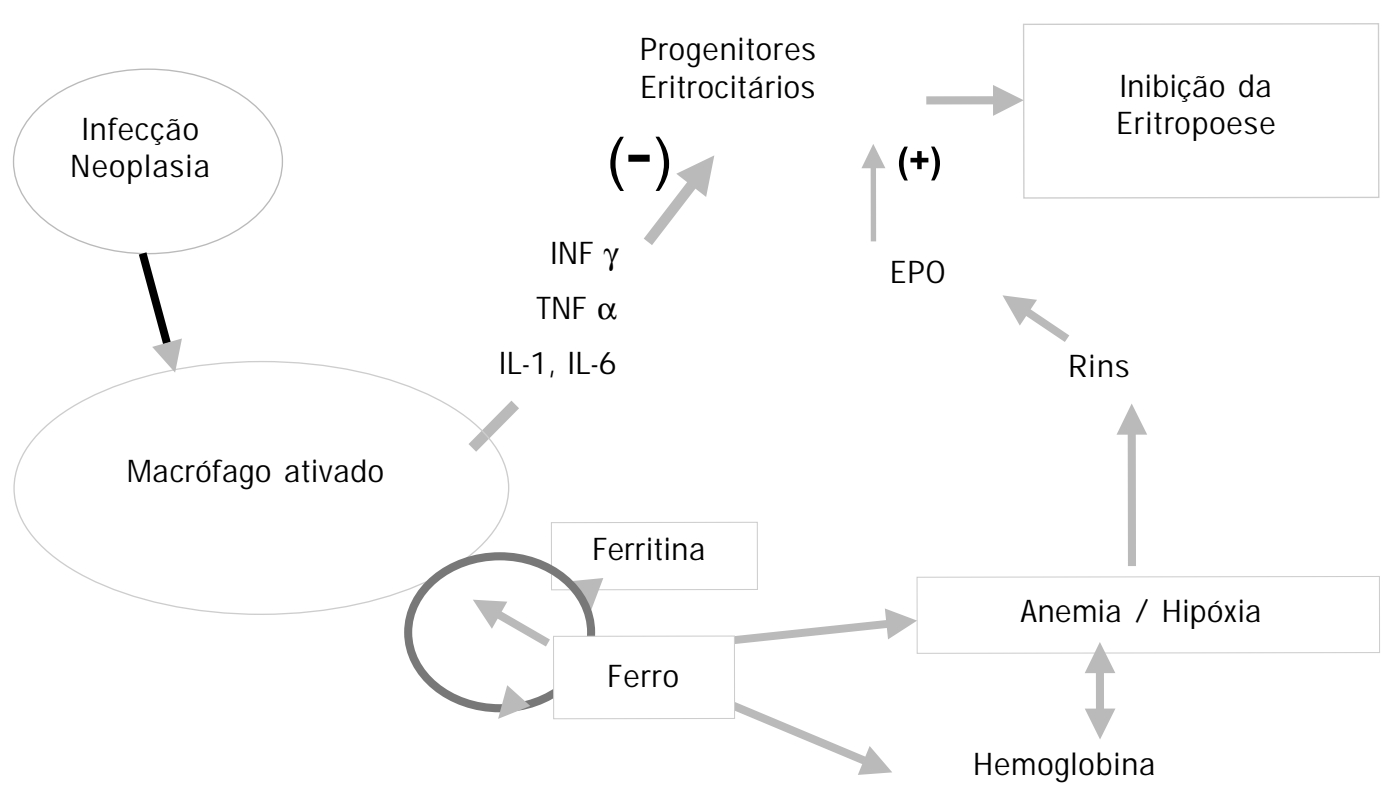

EPO = eritropoetina, IFN = interferon, IL = interleucina, TNF = fator de necrose tumoral

Figura 1. Representação esquemática da ação das citocinas sobre a eritropoese em pacientes com Anemia de Doença Crônica (modificado de Fuchs et al., 1991) (14) 
inflamatórias, principalmente da interleucina-1 e interleucina-6 (IL-1, IL-6), do fator de necrose tumoral alfa (TNF $\alpha$ ) e do interferon gama (INF $\gamma$ ), que atuam inibindo a proliferação dos precursores eritrocitários e, portanto, inibindo a eritropoese. Além disso, a ação supressora dessas citocinas sobre a eritropoese supera a ação estimuladora da EPO resultando na diminuição da resposta da medula óssea à EPO e à eritropoese (figura 1). In vitro, observa-se aumento significativo da proliferação de unidades formadoras de colônias eritrocitárias de pacientes com artrite reumatóide quando se adiciona anticorpo anti-TNF e anticorpo Anti-IL-1. 0 mesmo não é observado quando se adiciona anticorpo Anti-TNF $(9,14,17)$.

O utra alteração é a diminuição da oferta do ferro armazenado nos macrófagos levando à diminuição da eritropoese.

Na ADC observa-se discreta diminuição da sobrevida das hemácias, porém o principal mecanismo para o desenvolvimento da anemia resulta da incapacidade da medula óssea em aumentar sua atividade eritropoética suficientemente para compensar a menor sobrevida das hemácias. Isso é devido, basicamente, à ação de citocinas que atuam como supressores da eritropoese, tais como: $\operatorname{TNF} \alpha$, INF $\gamma$, e IL-1 $(5,12,17)$.

\section{D istúrbio do metabolismo do ferro}

0 ferro é um elemento essencial na maioria dos processos fisiológicos do organismo humano, desempenhando função central no metabolismo energético celular.

Em adultos normais, a quantidade de ferro absorvida diariamente equivale à quantidade excretada e o ferro do organismo é continuamente reciclado através de um eficiente sistema de reutilização deste metal das fontes internas, principalmente do ferro proveniente da hemoglobina das hemácias após hemólise intra e extravascular.

A maior parte do ferro plasmático destinase à medula óssea, sendo que $80 \%$ do ferro ligase ao heme e passa a fazer parte da hemoglobina como ferro funcional, e os $20 \%$ restantes

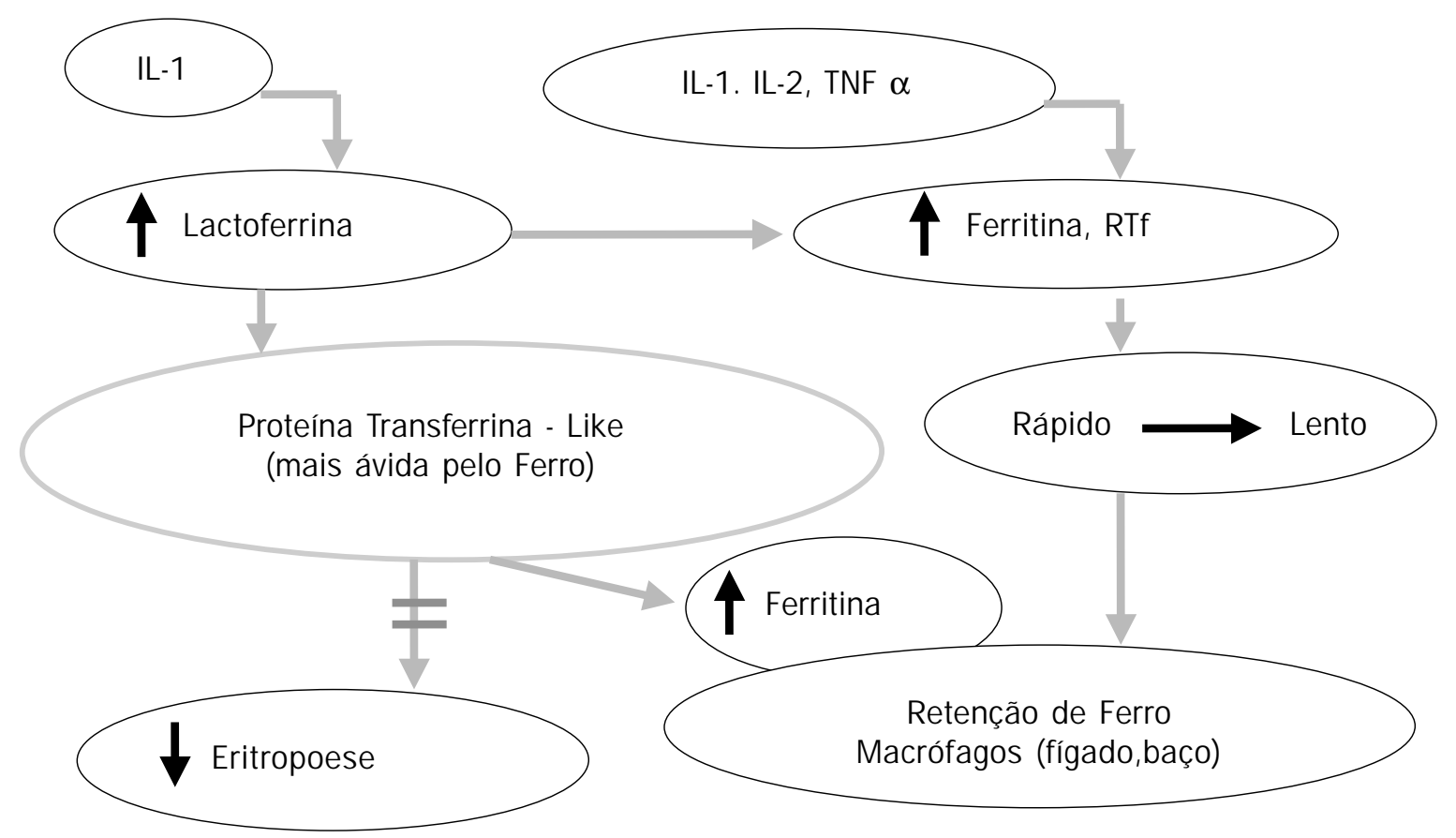

$\mathrm{IL}=$ interleucina, $\mathrm{TNF}=$ fator de necrose tumoral, $\mathrm{RTf}=$ receptor da transferrina

Figura 2. Represen tação esquemática da ação das citocinas e da lactoferrina no metabolismo do ferro em pacientes com Anemia de Doença Crônica (Jurado, R.L., 1997) (19) 
permanecem ligados à transferrina como ferro de transporte (18). Aproximadamente $25 \%$ do ferro do organismo de um adulto normal encontra-se armazenado, principalmente do fígado e do baço. Quando necessário, esse ferro retorna ao plasma e dirige-se à medula óssea para a formação de novas hemácias. Essa liberação do ferro armazenado ocorre didaticamente sob duas formas: forma lenta, proveniente do ferro de depósito e forma rápida ("pool" lábil), que é a forma que o organismo utiliza em situações de urgência (19).

Na ADC ocorre distúrbio da reutilização do ferro que se mantém sob a forma de depósito. Esse bloqueio deve-se ao aumento da síntese da lactoferrina, promovido pela IL-1, que é uma proteína semelhante à transferrina (transferrina-like) secretada pelos neutrófilos, que compete com essa. A lactoferrina difere funcionalmente da transferrina em três importantes aspectos: tem maior afinidade pelo ferro, especialmente em $\mathrm{pH}$ mais baixos, não transfere o ferro às células eritropoéticas e é "retida" rápida e ativamente pelos macrófagos. Portanto, dificulta a mobilização do ferro de depósito e, conseqüentemente, a eritropoese (19) (figura 2).

Vários estudos demonstraram a participação do Linfócito T ativado, que liberando IL-2, TNF $\alpha$ e INF $\gamma$ promovem a ativação dos macrófagos, que por sua vez, liberam IL-1, IL-6 e TNF $\alpha$ e atuam promovendo a retenção do ferro no sistema mononuclear fagocitário $(9,20)$. Além disso, o linfócito $T$ ativado inibe a ação do INF $\gamma$, que através da via do óxido nítrico e da transcrição do ácido ribonucléico mensageiro (RNAm) do receptor da transferrina promovem aumento da síntese de ferritina e dos receptores da transferrina, respectivamente, aumentando a captação e armazenamento do ferro no macrófago. Por outro lado, o linfócito T, principalmente via IL-4 e IL-13, estimulam a síntese de ferritina e dos receptores da transferrina, que resultam no aumento do ferro de depósito $(3,9,12,14,20)$ (figura 3).

Outra hipótese, que explica melhor o defeito da liberação do ferro dos hepatócitos e dos enterócitos, é o aumento da síntese da apoferritina, que por sua vez estimula a via lenta, favorecendo

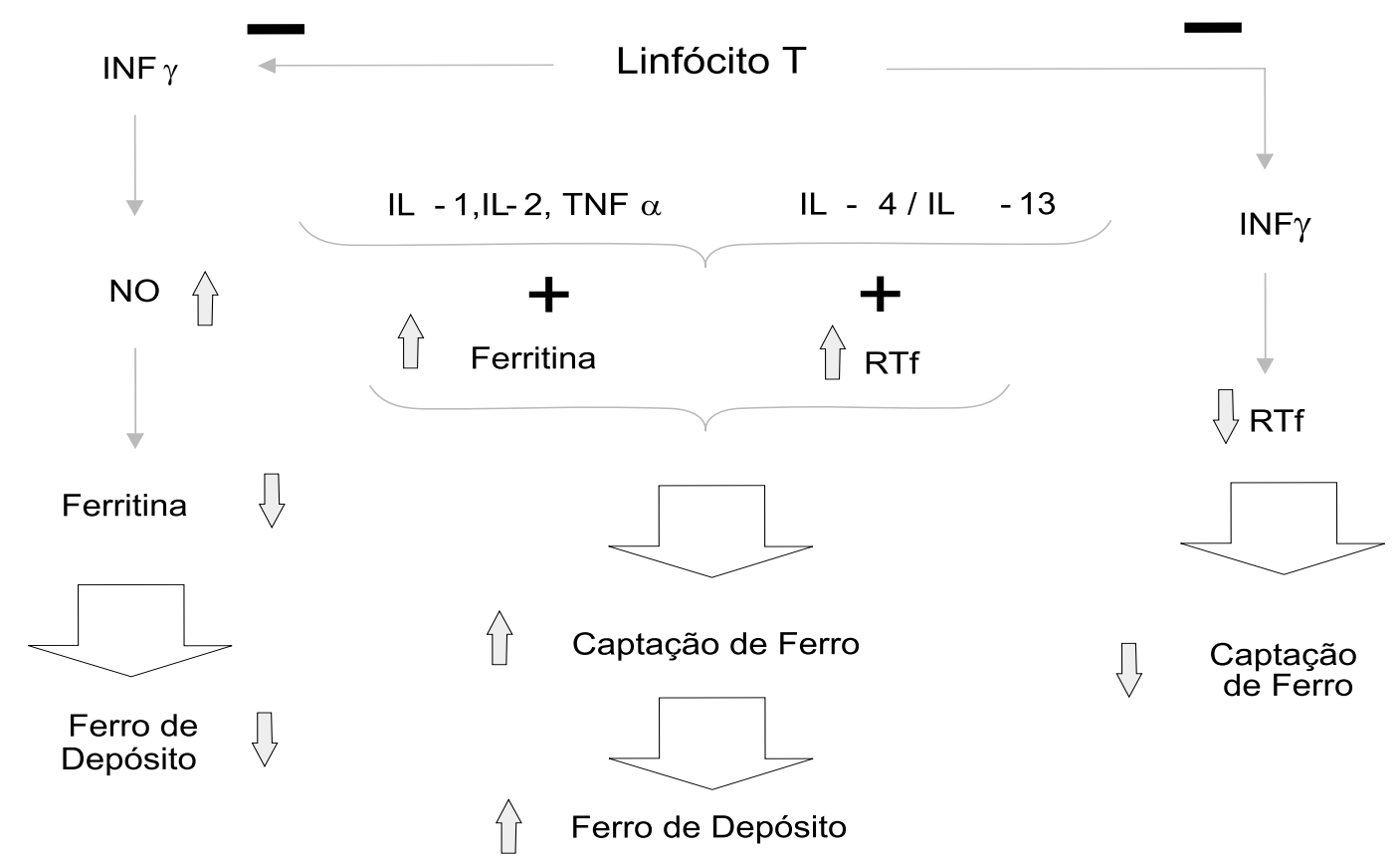

IFN $\gamma=$ interferon gama, IL = interleucina, NO = óxido nítrico, $\mathrm{RTf}=$ receptor da transferrina

Figura 3. Representação esquemática da ação das citocinas inflamatórias na regulação do metabolismo do ferro (modificado de Weiss et al., 1997) (20) 
Tabela 2. Mecanismos patofisiológicos en volvidos na ADC (Modificado de Means, R.T.Jr. 1999) (12)

\begin{tabular}{|l|l|l|}
\hline $\begin{array}{l}\text { Diminuição da sobrevida } \\
\text { das hemácias }\end{array}$ & $\begin{array}{l}\text { Defeito da mobilização/ } \\
\text { utilização do ferro }\end{array}$ & $\begin{array}{l}\text { Resposta medular } \\
\text { eritropoética } \\
\text { inadequada }\end{array}$ \\
\hline & $\begin{array}{l}\text { Aumento da síntese } \\
\text { de ferritina (IL-1, IFN } \alpha)\end{array}$ & $\begin{array}{l}\text { Síntese inadequada } \\
\text { de EPO frente à } \\
\text { anemia (IL-1, } \\
\text { TNF } \alpha, \text { TGF- } \beta \text { ) }\end{array}$ \\
\hline $\begin{array}{l}\text { Mecanismo(s) } \\
\text { desconhecido(s) } \\
\text { (IL-1, TNF } \alpha)\end{array}$ & $\begin{array}{l}\text { Aumento da síntese } \\
\text { dos receptores solúveis } \\
\text { da transferrina }\end{array}$ & $\begin{array}{l}\text { Inibição dos } \\
\text { progenitores } \\
\text { eritrocitários (IL-1, } \\
\text { TNF } \alpha, \text { INF } \gamma \text { ) }\end{array}$ \\
\cline { 2 - 4 } & Outros mecanismos \\
(TNF $\alpha$, IL-1) & $\begin{array}{l}\text { Diminuição da } \\
\text { expressão dos } \\
\text { receptores da EPO } \\
\text { (IFN } \gamma \text { ) }\end{array}$ \\
\hline
\end{tabular}

EPO = eritropoetina, IFN = interferon, IL = interleucina, TGF = fator de crescimento de tran sformação, TNF $=$ fator de necrose tumoral

a permanência do ferro sob a forma de depósito no interior dos macrófagos.

Em resumo, todo processo inflamatório crônico é capaz de aumentar a síntese e a liberação de citocinas endógenas que, por sua vez, induzem alterações do metabolismo do ferro e diminuição da síntese da hemoglobina (14). Na Tabela 2 relacionamos os principais mecanismos patofisiológicos envolvidos na ADC (12).

\section{Diagnóstico: Critérios Clínicos e Laboratoriais}

Cartw right \& Lee caracterizaram a ADC como "relativamente comum, mas clinicamente sem importância". Relativamente comum porque é a segunda causa mais freqüente de anemia, após a anemia ferropriva, e clinicamente sem importância porque, na maioria dos casos, caracteriza-se por anemia leve a moderada (21).

Quanto às características clínicas, geralmente os sintomas presentes estão relacionados à doença de base e não à anemia propriamente dita. Esta desenvolve-se nos primeiros 30 a 90 dias, usualmente não progride e, freqüentemente, normaliza-se com o tratamento da doença de base. Aspecto relevante é a correlação positiva entre anemia e atividade e/ ou intensidade da doença de base, ou seja, quanto maior a intensidade dos sintomas do paciente, maior o grau de anemia e, uma vez instituído o tratamento, a anemia tende a melhorar e, até mesmo, haver a normalização dos valores da hemoglobina. Assim, a presença e/ou intensidade da anemia constitui-se num parâmetro laboratorial utilizado para monitorar o curso clínico da doença bem como a eficácia do tratamento instituído (2).

Além dos dados clínicos, os parâmetros laboratoriais utilizados para o diagnóstico da ADC bem como para o diagnóstico diferencial com outras causas de anemia são: hemograma, morfologia eritrocitária, contagem de reticulócitos, ferro sérico, índice de saturação da transferrina, ferritina sérica, receptor da transferrina e análise do ferro medular.

ADC caracteriza-se por anemia normocítica/ normocrômica do tipo hipoproliferativa com ferro 
sérico e saturação da transferrina diminuídos e, paradoxalmente, aumento da concentração do ferro de depósito $(6,12,13)$.

$A$ anemia é de intensidade leve à moderada (hemoglobina entre 9 e $12 \mathrm{~g} / \mathrm{dl}$ ), raramente 0 valor da hemoglobina é inferior a $8 \mathrm{~g} / \mathrm{dl}$ e 0 hematócrito varia entre $25 \%$ e $40 \%$. As hemácias são normocrômicas e normocíticas, embora em $50 \%$ dos casos sejam hipocrômicas (concentração da hemoglobina corpuscular média varia entre $26 \mathrm{~g} / \mathrm{dl}$ e $32 \mathrm{~g} / \mathrm{dl}$ ) e, em 20 a $50 \%$, microcíticas. Entretanto, quando há microcitose, esta não costuma ser tão intensa quanto a observada no paciente com anemia ferropriva (raramente o volume corpuscular médio é inferior a 72 fl). À extensão do sangue periférico, pode-se observar anisocitose e poiquilocitose discretas, alterações estas menos evidentes que as encontradas na anemia ferropriva $(10,11,12)$. A contagem de reticulócitos é normal ou pouco elevada, ou melhor, inadequadamente aumentada em relação ao grau de anemia (13).

A ferritinemia encontra-se normal ou aumentada. Entretanto, como a ferritina é uma proteína de fase aguda, pacientes com doença inflamatória ou neoplásica podem apresentar valores normais ou elevados, porém, que não expressam de maneira correta a quantidade de ferro do organismo (22). Portanto, esses pacientes podem apresentar deficiência de ferro mesmo com valores normais de ferritinemia. Recente estudo retrospectivo, correlacionando a quantidade de ferro de depósito e a dosagem da ferritina sérica, evidenciou que cerca de $50 \%$ dos pacientes com ausência de ferro medular apresentavam ferritinemia dentro da normalidade, e um terço dos pacientes com deficiência de ferro apresentam valores de ferritina maiores que $100 \mathrm{ng} / \mathrm{ml}$ (23).

Paradoxalmente, a análise do ferro medular revela presença normal ou aumentada de ferro, que se deve, particularmente, ao distúrbio da sua mobilização e/ou reutilização pelos precursores eritrocitários hematopoéticos. A eritropoese encontra-se normal ou discretamente hiperplásica.

Outras alterações bioquímicas podem estar presentes no paciente com ADC, tais como: aumento do fibrinogênio e da proteína $C$ reativa, aumento da ceruloplasmina, diminuição da haptoglobina, aumento da velocidade de hemossedimentação, aumento do cobre sérico,

Tabela 3. Diagnóstico laboratorial diferencial entre Anemia de Doença Crônica e Anemia Ferropriva (modificado de Weiss, G., 2000) (3)

\begin{tabular}{|c|c|c|}
\hline $\begin{array}{c}\text { Teste } \\
\text { Laboratorial }\end{array}$ & ADC & Anemia Ferropriva \\
\hline $\begin{array}{c}\text { Ferro } \\
\text { sérico } \\
\text { Transferrina } \\
\text { sérica }\end{array}$ & diminuído ou normal & diminuído \\
\hline $\begin{array}{c}\text { Índice de } \\
\text { saturação da transferrina }\end{array}$ & diminuída ou normal & aumentada \\
\hline $\begin{array}{c}\text { Ferritina } \\
\text { sérica }\end{array}$ & diminuído ou normal & diminuído \\
\hline $\begin{array}{c}\text { Receptor } \\
\text { da transferrina }\end{array}$ & normal ou aumentada & diminuída \\
\hline $\begin{array}{c}\text { Receptor da transferrina / } \\
\text { Log ferritina }\end{array}$ & normal & aumentada \\
\hline diminuído $(<1)$ & aumentado (>4) \\
\hline
\end{tabular}

As palavras em negrito indicam a alteração mais freqüentemente observada 
diminuição da albumina e da transferrina sérica (6, 26, 27). A alteração desses parâmetros tem relação direta com a fase aguda da doença de base e podem ser utilizados para monitorar o curso clínico da doença e a eficácia do tratamento instituído.

A dosagem sérica das citocinas: IL-1, II-6, TNF $\alpha$ e INF $\gamma$ encontra-se aumentada e da eritropoetina, normal ou pouco aumentada (14).

\section{Diagnóstico D iferencial}

A ADC pode coexistir com anemia por deficiência de ferro, deficiência de folato e/ou vitamina B12, hemólise, diminuição da eritropoese por insuficiencia renal, mielofitise, induzida por drogas ou toxinas. Portanto, essas alterações devem ser investigadas e excluídas.

0 diagnóstico diferencial mais importante com ADC é anemia ferropriva (13). Na prática clínica, ferritina sérica inferior a $12 \mathrm{ng} / \mathrm{ml}$ confirma o diagnóstico de deficiência de ferro, enquanto que valores acima de $200 \mathrm{ng} / \mathrm{ml}$ praticamente excluem esse diagnóstico, mesmo em pacientes com doença inflamatória ou neoplásica.

Desta forma, vários autores têm proposto que, para os pacientes com doença inflamatória ou neoplasia, o limite inferior de normalidade para a ferritina deva ser próximo de $30 \mathrm{ng} / \mathrm{ml}$ (23), comparado com o valor de corte normalmente utilizado para deficiência de ferro que é de ferritina menor ou igual a 12 ou $10 \mathrm{ng} / \mathrm{ml}$. Para valores entre $30 \mathrm{ng} / \mathrm{ml}$ e $100 \mathrm{ng} / \mathrm{ml}$, a determinação da concentração dos receptores da transferrina (RTf) e, mais precisamente, do índice RTf/Log ferritina são de grande importância para confirmar ou não a existência de deficiência de ferro nesses pacientes $(23,24,25,28,29)$.

Os testes laboratoriais bem como seus resultados característicos observados nestas duas condições específicas podem ser observados na tabela 3 .

\section{Tratamento}

0 tratamento específico da ADC consiste no tratamento da doença de base com o objetivo de corrigir os mecanismos envolvidos no desenvolvimento da anemia (9). O uso de terapia anti-citocina pode oferecer algum benefício ao paciente, porém sua utilização ainda é controversa (30).

A anemia no paciente com ADC costuma ser leve à moderada e, em menos de $2 \%$ dos casos, 0 hematócrito é inferior a 25\% (10).

Estima-se que $20 \%$ a $30 \%$ dos pacientes requerem tratamento que inclui: reposição de ferro, administração da eritropoetina e, eventualmente, transfusão de hemácias. Tais medidas devem ser consideradas caso a caso (11, $12,13)$.

O ferro é um elemento essencial na maioria dos processos fisiológicos, desempenhando função central no metabolismo energético celular. No caso das infecções e das neoplasias em que o agente etiológico e as células neoplásicas dependem intrinsicamente do ferro para sua proliferação, alguns estudiosos adotam a hipótese de que a retenção de ferro na forma de depósito constitui-se um mecanismo desenvolvido pelo organismo humano como forma de defesa contra esses agentes agressores. Assim, nesses casos, deve-se evitar a administração de ferro oral ou parenteral. Já nas doenças inflamatórias como na artrite reumatóide, recomenda-se o uso do ferro, quando necessário (7, 31, 32).

A administração da eritropoetina (EPO) deve ser considerada nas doenças inflamatórias agudas ou crônicas, cuja atividade da doença é prolongada e a intensidade da anemia compromete a qualidade de vida do paciente. Recomenda-se a dose inicial de eritropoetina de $100 \mathrm{U} / \mathrm{Kg}$, por via subcutânea, dividida em três doses semanais por um período de, pelo menos, 8 a 12 semanas. Se, após 8 a 12 semanas, não houver resposta terapêutica desejada ou esperada, recomenda-se aumentar a dose de EPO para $150 \mathrm{U} / \mathrm{Kg}$ até 300 $\mathrm{U} / \mathrm{Kg}$. Além disso, recomenda-se a administração concomitante do ferro oral ( $325 \mathrm{mg} / \mathrm{dia}$ ), mesmo nos pacientes com estoques adequados de ferro. Isto se justifica pelo distúrbio da mobilização e/ ou reutilização do ferro do organismo, mecanismo patofisiológico característico na $\operatorname{ADC}(12,33,34)$.

A transfusão de concentrado de hemácias pode ser necessária, especialmente nos pacientes mais idosos e nos pacientes com neoplasia, nos quais outros mecanismos (como: supressão da 
hematopoese pós quimioterapia, infiltração da medula óssea) possam estar envolvidos no desenvolvimento da anemia (3). Portanto, compreendem situações cuja intensidade da anemia compromete a qualidade de vida e coloca em risco a sobrevida do paciente.

\section{Anemia of chronic disease \\ Rodolfo D. Cançado, Carlos S. Chiattone}

\section{Abstract}

The anemia of chronic disease (ACD) is usually defined as the anemia occurring in chronic infectious, inflammatory disorders, or neoplastic diseases, and is one of themost common syndromes in the clinical practice. Characteristically, ACD is a mild-to-moderate, normochromic/normocytic anemia, and is characterized by hypoferremia in the presence of adequate iron stores.

The three principal pathologic mechanisms involved in ACD are: reduced erythrocyte survival, bone marrow failure to increase red blood cell production to compensate for the increase in its demand, and abnormal mobilization of reticuloen dothelial iron stores. The central role of monocytes and macrophages, and the increased production of the cytokines that mediate the immune or inflammatory response, such as tumor necrosis factor, interleukin-1 and the interferons, are implicated in all three processes involved in the development of ACD.

The aim of this article is to review the recent advances in the understanding of the pathophysiologic, diagnostic and therapeutic aspects of this syndrome.

Rev.bras. hematol.hemoter.,2002,24(2):127-136

Keywords: Anemia of chronic disease, erythropoiesis, cytokines, tumor necrosis factor, interleukin, interferon

\section{Referências Bibliográficas}

1. Hansen NE. The anemia of chronic disorders: A bag of unsolved questions. Scand. J. H aematol. 1983; 31:397.

2. Lee GR. Theanemia of chronic disease. Semin.
H ematol. 1983; 20:61-80.

3. Weiss G. Advances in the diagnosis and management for the anemia of chronic disease. H ematology 2000. 2000; 42-45.

4. Denz $H$, Fuchs $D$, Wachter $H$. Altered iron metabolism and the anemia of chron ic disease: a role of immune activation. Blood 1992; 79:2797.

5. Spivak JL. The blood in systemic disorders. Lancet 2000; 355: 1707-1712.

6. Cartwright GE. The anemia of chronic disorders. Semin. H ematol. 1966; 3:351-375.

7. Haurani FI, Green D. Primary defective iron reutilization. Am. J. M ed. 1967; 42:151.

8. Shilling RF. Anemia of chronic disease: a misnomer Ann. Int. M ed. 1991; 115:572-573.

9. Weiss G. Iron and anemia of chronic disease. Kidney Int. 1999; 69:12-17.

10. Cash JM, Sears DA. The anemia of chronic disease: spectrum of associated diseases in a series of unselected hospitalized patients. Am. J. Med. 1989; 87:638-644.

11. Baer AN, Dessypris EN, Krantz SB. The pathogenesis of anemia in rheumatoid arthritis: a clinical and laboratory analysis. Semin. Arthritis R heum. 1990; 14:209-223.

12. Means RTJr. Advances in thean emia of chronic disease. Int. J. H ematol. 1999; 70:7-12.

13. Means RTJr, Krantz SB. Progress in understan ding the pathogen esis of the anemia of chronic disease. Blood 1992; 80:1639-1647.

14. Fuchs $D$, Hausen $A$, Reibnegger $G$, Werner ER, Werner-Felmayer G, Dierich MP, Wachter $H$. Immune activation and the anaemia associated with chronic inflammatory disorders. Eur. J. H aematol. 1991; 46:65-70.

15. Fillet $G$, Beguin $Y$, Baldelli L. Model of reticuloendothelial iron metabolism in humans: abnormal behavior in idiopathic hemochromatosis and in inflammation. Blood, 1989; 74:844-851.

16. Moura E, Noordermeer MA, Verhoeven N, Verheul AF, Marx JJ. Iron release from human monocytes after erythrophagocytosis in vitro: an investigation in normal subjects and hereditary hemochromatosis patients. Blood 1998; 92:2511-2519.

17. Katevas P, Andonopoulos AP, Kourakli- 
Symeonidis A, Manopoulos E, Lafi T, Makri M, Zoumbos NC. Peripheral blood mononuclear cells from patients with rheu matoid arthritis suppress erythropoiesis in vitro via production of tumor necrosis factor alpha. Eur. J. H aematol. 1994; 53:26-30.

18. Andrews NC. Disorders of iron metabolism. N . Engl. J. M ed. 1999; 341:1986-1995.

19. Jurado RL. Iron, infections, and anemia of inflammation. Clin. Infect. D is. 1997; 25: 888-895.

20. Weiss G, Bogdan C, Hentze MW. Pathways for the regulation of macrophage iron metabolism by theanti-inflammatory cytokines IL-4 and IL-13. J. Immunol. 1997; 158: 420425.

21. Cartwright GE, Lee GR. The anemia of chronic disorders. Br. J. H aematol. 1971; 21:147-152.

22. Birgegard $G$, Hallgren $R$, Killander $A$, Stromberg $A$, Venge $P$, Wide $L$. Serum ferritin during infection. A longitudinal study. Scand. J. H aematol. 1978; 21: 333-340.

23. North M, Dallalio G, Donath AS, Melink R, Means RT. Serum transferrin receptor levels in patients undergoing evaluation of iron stores: correlation with other parametersand observed versus predicted results. Clin. Lab. H aematol. 1997; 19:93-97.

24. Punnonen K, Irjala K, Rajamäki A. Serum transferrin receptor and its ratio to serum ferritin in the diagnosis of iron deficiency. Blood 1997; 1052-1057.

25. Mast AE, Blinder MA, Gronowski AM, Chumley $C$, Scott MG. Clinical utility of the soluble transferrin receptor and comparison with serum ferritin in several populations. Clin. Chem. 1998; 44:45-51.

26. Morley JJ, Kushner I. Serum C-reative protein levels in disease. Ann. N.Y. Acad. Sci. 1982; 389:406-418.
27. Kushner I. The phenomenon of the acute phase response. Ann. N.Y. Acad. Sci. 1982; 389:39-48.

28. Huebers HA, Beguin $Y$, Pootrakul P, Einspahr $D$, Finch CA. Intact transferrin receptors in human plasma and their relation to erythropoiesis. Blood 1990; 75:102-107.

29. Means RTJr, Allen J, Sears DA, Schuster SJ. Serum soluble transferrin receptor and the prediction of marrow aspirateiron results in a heterogeneous group of patients. Clin. Lab. H aematol. 1999; 21:161-167.

30. Means RTJr, Krantz SB, Luna J, Marsters SA, Ashkenazi $A$. Inhibition of murine erythroid colony formation in vitro by interferon gamma and correction by interferon receptor immunoadhesin inhibitor. Blood 1994; 83:911-915.

31. Auerbach $M$, Witt $D$, Toler $W$, Fierstein $M$, Lerner RG, Ballard $\mathrm{H}$. Clinical use of the total dose intravenous infusion of iron dextran. J. Lab. Clin. M ed. 1988; 111: 566-570.

32. Martini A, Ravelli A, Di Fuccia G, Rosti V, Cazzola M, Barosi G. Intraven ousiron therapy for severe anaemia in systemic-on set juvenile chronic arthritis. Lancet 1994; 344:1052-1054.

33. Pincus T, Olsen NJ, Russell IJ, Wolfe F, Harris ER, Schnitzer TZ, Boccagno JA, Krantz SB. Multicenter study of recombinant human erythropoietin in correction of anemia in rheumatoid arthritis. Am. J. Med. 1990; 89:161-168.

34. Gudbjornsson B, Hallgren R, Wide L, Birgerard $G$. Response of anaemia in rheumatoid arthritis to treatment with subcutaneous recombinant human erythropoietin. Ann. Rheum. D is. 1992; 51:747-752.

Recebido - 18/03/2002

Aceito - 13/06/2002 